IX Congresso Brasileiro de Informática na Educação (CBIE 2020)

Anais do XXXI Simpósio Brasileiro de Informática na Educação (SBIE 2020)

\title{
Ressignificação de territórios: A Realidade Virtual no acesso a outros povos e culturas.
}

\author{
Francisco José Carvalho Costa ${ }^{1}$, Ana Amábile Gabrielle Rodrigues Leite ${ }^{2}$, Duana \\ de Souza Cunha ${ }^{2}$
}

${ }^{1}$ Universidade Estadual do Piauí (UESPI)

Parnaíba - PI - Brazil

${ }^{2}$ Universidade Federal do Delta do Parnaíba (UFDPar)

Parnaíba - PI - Brazil

\{franciscojoseatdl3, anaamabilegabrielle, duanacunha\}@gmail.com

\begin{abstract}
This paper deals with a research experience that aims to understand the impacts of Virtual Reality on education, as a proposal for mediation in the construction of knowledge about other peoples and cultures, for this, a sample of immersion in virtual reality presented to the students of the course of Human Sciences, the daily lives of an African family and indigenous peoples in the Amazon rainforest. This quantitative-qualitative research used an electronic form for data collection, adapted from the Atracdiff model of user experience analysis (UX), with open and closed questions and the data analysis was based on concepts of Historical-Dialectical Materialism.
\end{abstract}

Resumo. Este trabalho versa sobre uma experiência de pesquisa que tem como objetivo entender os impactos da Realidade Virtual na educação, como proposta de mediação na construção do conhecimento sobre outros povos e culturas, para isto, uma mostra de imersão em realidade virtual apresentou aos estudantes do curso de Ciências Humanas, o cotidiano de uma família africana e de povos indígenas na floresta na amazônica. Esta pesquisa, de caráter quantitativoqualitativo, utilizou de um formulário eletrônico para coleta de dados, adaptado do modelo Atracdiff de análise de experiência do usuário (UX), dispondo de perguntas abertas e fechadas e a análise dos dados se baseou em conceitos do Materialismo Histórico-Dialético.

\section{Introdução}

A conceituação de espaço, território e lugar, propiciada pela ciência do estudo dos objetos de natureza espacial, a geografia, carrega consigo a pluralidade de significações que cada corrente de pensamento, agregadas a cada conceito, estabelece a elas. À luz da discussão que aqui se constrói, os conceitos de espaço, lugar e território, que são naturalmente tangenciados pelo aspecto material - físico geográfico -, serão (re)interpretados a partir do amago dos ecossistemas midiáticos digitais.

A realidade material, referente ao objeto tocável, é um dos pontos que requer análise para então construímos uma reinterpretação conceitual-geográfica das conjunturas tecnológicas digitais. $\mathrm{O}$ virtual, conceito que nasce da emergência das conexões de massa em rede, potencializou um novo olhar para a discussão de significados e entendimento do que é ou não realidade. Em convergência com a psicanálise, em que a realidade psíquica é um modo de lidar com o factual, Freud ${ }^{1}$ embasa conceitos de realidade psíquica e

\footnotetext{
1 “A primeira vez em que Freud (1950a [1895]/1996) aborda a questão da existência de diferentes tipos de realidade, denominadas por ele como "realidade do pensamento" e "realidade externa", é em 1895, no Projeto para uma psicologia científica”. (LEANDRO et al., 2013)
} 
IX Congresso Brasileiro de Informática na Educação (CBIE 2020)

Anais do XXXI Simpósio Brasileiro de Informática na Educação (SBIE 2020)

material e como eles se inter-relacionam. Ao abordar estas questões, e construirmos uma análise tangente à prática do pensamento, é possível imaginar certa polarização dos conceitos, contudo, Freud descarta tal dicotomia ao fomentar a imaginação como mediação entre a "realidade do pensamento" e a "realidade material".

Dito isto, pode-se entender a "realidade do pensamento" como uma maneira de entender a "realidade material" ou exterior. A imaginação, ainda em aspecto da psicanálise, não se constitui do inexistente, mas, da maneira como o indivíduo interpreta para si a sua narrativa particular ${ }^{2}$. Face a este desdobramento de que a imaginação não compõe o irreal tampouco tem caráter contraceptivo do material, é pertinente compreender como o virtual converge suas significações na construção de uma realidade (in)material e suas implicações na educação formal.

A expansão do acesso facilitado às mídias digitais coincide com a necessidade da abstração de um novo olhar sob os espaços educacionais e as influências que esses espaços têm sofrido. E é em decorrência desta influência que esta pesquisa emergiu. A educação construída por indivíduos submersos a cultura digital, compreende a possibilidade de inserção de artefatos tecnológicos nos ambientes fraccionais levando-se em consideração a sua potencialidade mediadora.

Ao interpretar a cultura digital como uma construção do constante e do plural acesso à tecnologias digitais, deparamo-nos com a ressignificação do que são espaço, território e lugar e sob esta tessitura de ecossistema digital, nasce a conjuntura do ciberespaço, concepção preconizada por William Gibson (2015) trilogia do Sprawl, ficção cientifica que descreve um universo de atividade paralela ao material, onde os indivíduos interagem com uma extensão particular de sua própria existência (GIBSON2015).

No diálogo entre a realidade educacional com a sensibilidade do "universo" digital, potencializamos a ruptura dos espaços físicos como sendo os únicos e possíveis ambientes formativos, reinventado o acesso à educação possibilitado a qualquer hora e lugar, com acesso à rede, que se deseje (SANTAELLA, 2013). A virtualização proporciona não somente aceso às construções de narrativas verbais, mas também àquilo que perfaz a narrativa não verbal, concebendo assim a realidade imagética.

A Realidade Virtual (RV), como a tecnologia que nasce da combinação entre hardwares e softwares sensíveis ao movimento, compreende o objeto de mediação desta pesquisa, que tem como objetivo entender como a computação ubíqua, caracterizada pela RV podem impactar no conhecimento e entendimento de estudos sobre territórios distintos, partindo da problemática da dificuldade de locomoção e acesso aos locais estudados em sala de aula.

Neste intento, esta pesquisa visa reformular a significação de características geográficas como apenas aquilo que é físico, possibilitando, por meio da extensão aos espaços virtuais, o acesso a diferentes territórios. Para entender os impactos da realidade virtual no estudo de novos territórios e suas características geográficas e humanas, no sentido cultural, apresentamos a alunos do ensino superior do curso de Ciência Sociais, imagens projetadas em RV

A imagens utilizadas apresentam narrativas cotidianas de povos indígenas no Brasil e o cotidiano de uma jovem no continente africano. Todas as imagens, em formato 3D

\footnotetext{
${ }^{2}$ Introdução da imaginação como mediação das realidades psíquica e material, onde Freud “[...] instituiu o conceito de realidade psíquica [como] núcleo irredutível do psiquismo, registro dos desejos inconscientes dos quais a fantasia é a expressão máxima e mais verdadeira”. (ROUDINESCO et al., 1998, p. 224).
} 
IX Congresso Brasileiro de Informática na Educação (CBIE 2020)

Anais do XXXI Simpósio Brasileiro de Informática na Educação (SBIE 2020)

para RV são de livre acesso em plataforma online de vídeos, YouTube, efetivando assim a prática de vivência ubíqua na formação de novos espaços, além do tradicionalmente físico. De modo a compreender melhor os conceitos advindos da cibercultura, a projeção teórica da próxima sessão sistematiza e analisa a influência de termos e seus significados na construção e formação de (novos) significados.

\section{Aporte Teórico}

A linguagem, enquanto matéria prima da comunicação, é tida para a linguística como um conjunto de signos vocais arbitrários (BORDENAVE, 2017), e carrega a responsabilidade factual de desempenhar a construção de sentido na relação comunicativa. Com o acesso facilitado às redes digitais, a comunicação se potencializou, a reconfiguração dos mecanismos comunicacionais sistematizou a convergência dos meios digitais e a conexão em massa, permitindo o acesso a informação à distância (SANTAELLA, 2016).

Neste desdobramento, a máquina objeto do computador configura a porta de entrada à emergência das mídias, uma vez que ele incorpora todas as mídias que o antecederam - ao considerar as mídias não digitais - (MITTERMAYER, 2017), contudo, foi a transgressão ao aparelho móvel que fez emergir novos conceitos e possibilidades (SANTAELLA, 2016), a começar pela mídia em movimento e o endossar da cultura virtual.

Antes de abordar concepções acerca do virtual, é pertinente compreender a mobilidade não como uma emergência das mídias, mas como uma característica possível e inegável ao contexto histórico humano Santaella (2016 apud lemos 2010); e deste modo, a mobilidade computacional pode ser entendida como uma potência do móvel que é particular aos sujeitos. Ao conceituar o virtual, Levy (2011) o evidencia como uma potência, confrontando a pertinência do termo e a demasiada análise que o opõe ao real.

Para o autor (ibid. p. 16), o virtual compreende o ato, e a virtualização compreende a dinâmica, sendo assim, a virtualização não configura uma desrealização, ou seja, uma transformação de uma realidade em outra, mas o deslocamento do "centro de gravidade ontológico do objeto considerado" (ibid. p.17), compreende-se então, que a cultura da mobilidade provocou novas capacidades físicas e digitais nos seres humanos.

Das provocações destacáveis, é notória a efervescência do conceito de ubiquidade, que de modo geral, permite aos indivíduos a, a priori, conflituosa presença em dois espaços ao mesmo tempo (SANTAELLA, 2016). A formação da perspectiva de ubiquidade, diz da conversão da mobilidade no efeito do objeto movente e pervasividade na sensibilidade aos contextos, a presença imaterial, como os dados acessíveis pela internet, por exemplo (SANTAELLA, 2013).

Dadas as potencialidades advindas da tecnologia ubíqua, nasce a ressignificação possível e convergência de conceitos, um destes, à luz desta pesquisa, a combinação da realidade material tangente aos espaços físicos, e a transgressão dos espaços para o virtual no campo midiático, tendo assim a realidade virtual. Pode-se caracterizar, além de combinativa, a existência da realidade virtual com um espaço intersticial.

Ao combinar a dinâmica dos espaços físico e virtual, Santaella (2010) caracteriza os "espaços intersticiais, ou seja, misturas inextricáveis entre os espaços físicos e o ciberespaço, possibilitadas pelas mídias móveis”. (LAVALLE, 2017) aponta a Realidade Virtual (RV) como uma técnica que potencializa um comportamento um comportamento especifico em um indivíduo usando estimulação sensorial artificial, enquanto ele tem pouca ou nenhuma consciência interferência do sistema em sua realidade inicial. 
IX Congresso Brasileiro de Informática na Educação (CBIE 2020)

Anais do XXXI Simpósio Brasileiro de Informática na Educação (SBIE 2020)

Ainda, pode-se caracterizar a RV como uma projeção computacional interativa que transfere informações sensoriais ao usuário (ABARI et al., 2017). Como conclui (FERNANDEZ, 2017), tal tecnologia possibilita aos usuários a imersão a um ambiente previamente programado que simula uma realidade; a conotação da realidade virtual como uma tecnologia digital evidencia uma reestruturação da ideia de espaço, território e espaço geográfico.

A respeito desses conceitos, Tonucci (2013) apresenta uma discussão à luz da geografia crítica aonde apresenta a concernência do espaço e do território com as influencias histórico-sociais no contexto da espacialização/territorialização. De modo geral, pode-se evidenciar o território como uma interdependência universal dos lugares e lugar como "conjunto indissociável de sistemas de objetos e sistemas de ações" (ibid.,2013).

Aprofundando a discussão sobre território, Tonucci (2013 apud Haesbaert, 2012) apresenta uma indefinição conceitual clara de "território" nos debates sobre a desterritorialização, interpretada de maneira plural em relação à (re)territorialização, e enviesada à predominância das redes - como uma oposição ao território material. Em convergência à construção de Levy (2011), que apresenta o virtual como uma desterritorialização em que os conceitos de espaço-tempo se refazem no contato com o ciberespaço, Haesbaert (2012) presenta a "multiterritorialidade", interpretada como processo simultâneo de construção e destruição de territórios em diferentes modalidades tratando também do território-rede.

Uma vez inserida no cotidiano escolar, a imersão em Realidade Virtual pode ser entendida como um complexo de possibilidades para os ambientes formacionais, tal imersão em conduz os alunos a um "novo" ambiente de realidade paralela aonde se aplica uma dimensão física e espacial à compreensão e aprendizagem do aluno (YILDIRIM et al., 2018).

Dessa maneira, cita Black(2017) que a sensação de contato com outros lugares proporcionada pelos ambientes de Realidade Virtual pode ser considerado muito eficaz; uma vez que tal sensibilidade pode ajudar em situações que necessitem de locomoção para aulas que envolvam o conhecimento sobre outros territorios. Eentede-se então, que a RV aproxima estudantes e professores dos territorios estudados, o que constroi de maneira dinamica a aprendizagem e o entendimento.

\section{Metodologia}

Sob o intuito de potencializar acesso a outros povos e culturas, esta pesquisa foi constituída sob o aspecto etnográfico, abordando uma metodologia quantitativaqualitativa, no contexto de uma mostra de imersão em realidade virtual com $12^{3}$ alunos no curso de Ciências Humanas da Universidade Federal do Maranhão - UFMA em uma cidade no interior do estado, São Bernardo- MA, . Buscando entender como a Realidade Virtual (RV) poderia ajudar na construção de conhecimento mais próxima das realidades estudadas.

Para isso, 5 óculos RV foram usados para exibir dois vídeos disponibilizados, gratuitamente, pelo YouTube em um canal de promoção à conscientização sobre preservação ambiental, na ocasião, os vídeos utilizados foram escolhidos por

\footnotetext{
${ }^{3} \mathrm{O}$ número de participantes proposto foi de 35 alunos, contudo, a data da mostra coincidiu com a data de início da paralização de atividades devido a pandemia do novo coronavirús.
} 
IX Congresso Brasileiro de Informática na Educação (CBIE 2020)

Anais do XXXI Simpósio Brasileiro de Informática na Educação (SBIE 2020)

apresentarem o cotidiano de povos africanos e indígenas brasileiros, e se tratarem de vídeos gratuitos em formato 3D-RV, o que facilitou a usabilidade e exibição utilizando os óculo RV. Ao final da experiência de imersão, um questionário online foi disponibilizado aos participantes por meio do Google Forms.

\subsection{Ambientação e objetos de análise}

O canal Conservação Internacional ${ }^{4}$ (CI), organizou e disponibilizou o vídeo "Amazônia adentro" em formato 3D, onde a experiência é caracterizada por uma aventura virtualizada, na maior floresta tropical do mundo, a Amazônia. A história exibida no vídeo é narrada por integrante de uma comunidade indígena, não nomeada no vídeo ou descrições dele, o vídeo é filme, como descrito no resumo textual, foi produzido no interior da floresta e se dá como um convite à preservação da floresta.

O segundo vídeo, também em RV, narra o dia a dia de uma cidadã africana, e de seus familiares no contato com seus costumes religiosos e de trabalho. Sob o título "Minha África" 5 ", a narrativa midiática, leva os usuários da tecnologia ao ambiente natural, selvagem, do Quênia. A jovem Samburu - nomenclatura que define a cultura do povo seminômades, pastores, que vivem ao norte do Quênia - conta como as vidas selvagem e humana estão diretamente interligadas, enquanto salva um filhote de elefante e conduz caprinos pela região aonde mora.

\subsection{Levantamento e Análise de dados}

Baseado no questionário de análise de experiência de usuário (UX), elaboramos uma adaptação do formulário AttrackDiff ${ }^{6}$. O questionário aborda três dimensões e apresenta nelas descritores, acompanhado de uma escala de palavras (Tabela 1), visando potencializar maior fidelidade, por parte dos participantes, as palavras não foram organizadas seguindo um padrão, cada descritor se configura com um índice dos gráficos de acordo com cada categoria.

O dimensionamento visa transcrever as sensações evidenciadas pelos usuários no contato com o objeto estudado, para isso, para cada palavra do questionário descreve uma sensação, um conjunto escalar de cinco palavras foi colocado à disposição dos participantes que podiam concordar ou não com cada descrição.

Tabela 1 - escala de palavras

\begin{tabular}{|c|c|c|c|c|c|}
\hline $\begin{array}{c}\text { Descritor } \\
\text { (AttrackDiff) }\end{array}$ & $\begin{array}{c}\text { Discordo } \\
\text { plenamente }\end{array}$ & discordo & Neutro & Concordo & $\begin{array}{c}\text { Concordo } \\
\text { plenamente }\end{array}$ \\
\hline
\end{tabular}

Qualidade Pragmática (QP), Qualidade Hedônica e (c) Atratividade, são as categorias estabelecidas para a projeção das sensações dos usuários. A "Qualidade Pragmática", visa conhecer o grau de sucesso com o que os usuários atingem os objetivos esperados pelo uso do produto ou aplicação, em relação a "Qualidade Hedônica", esta se preocupa em elencar fatores como originalidade, interesse e estímulo, e a dimensão "Atratividade" baseado na percepção da qualidade (VALENTIM et al., 2015).

A adaptação seguiu sua construção à luz da análise do Materialismo Histórico Dialético $(\mathrm{MDH})$, por meio de perguntas abertas junto à escala de palavra. O "MHD diz

\footnotetext{
${ }^{4}$ Disponibilizado na plataforma digital YouTube: https://youtu.be/GC6ejxKwbFw

${ }^{5}$ Disponível em: https://youtu.be/SqQCGf6GoLE

${ }^{6}$ Disponível em: http://attrakdiff.de/
} 
IX Congresso Brasileiro de Informática na Educação (CBIE 2020)

Anais do XXXI Simpósio Brasileiro de Informática na Educação (SBIE 2020)

respeito à análise dos fenômenos sociais e de seu processo histórico" (COSTA et al., 2020, p.05), por se tratar de uma pesquisa elaborada em ambiente interdisciplinar, em que aspectos computacionais mediam acesso a novos contextos, visamos por meio das discussões feitas pelos participantes, entender como foi a interpretação e as sensações despertadas no aceso ao ambiente virtual.

A apresentação e discussão de dados se deu de modo categórico, aonde cada uma das competências do modelo de análise utilizado atua como uma categoria, apresentando os dados e discussões referentes, além disso, os levantamentos discursivos que se adequam a cada categoria, acompanham o conjunto de dados referente. Tal categorização visa estabelecer uma projeção dialética aos potenciais aspectos sensíveis apresentados nas competências do modelo UX por meio de convergência da discussão com tópicos da literatura.

\section{Resultados e discussões}

Objetivando entender como a figuração da computação ubíqua, na condição de Realidade Virtual impacta a educação separamos essa sessão em três categorias, cada categoria é baseada nas dimensões do questionário modelo - AttrackDiff: Qualidade Pragmática (QP), Qualidade Hedônica e (c) Atratividade.

\subsection{Qualidade pragmática}

Inicialmente, discutiremos sobre a qualidade pragmática onde se analisa a qualidade da experiência e o grau de sucesso que os usuários obtiveram no uso do objeto estudado: Esta dimensão descreve a qualidade de uma aplicação, neste sentido, podemos analisar o quão familiarizado com o uso dos ósculos os participantes estavam e o ponto de vista deles sobre a as características usuais da realidade virtual com auxílio dos óculos.

Gráfico 1 - Qualidade pragmática

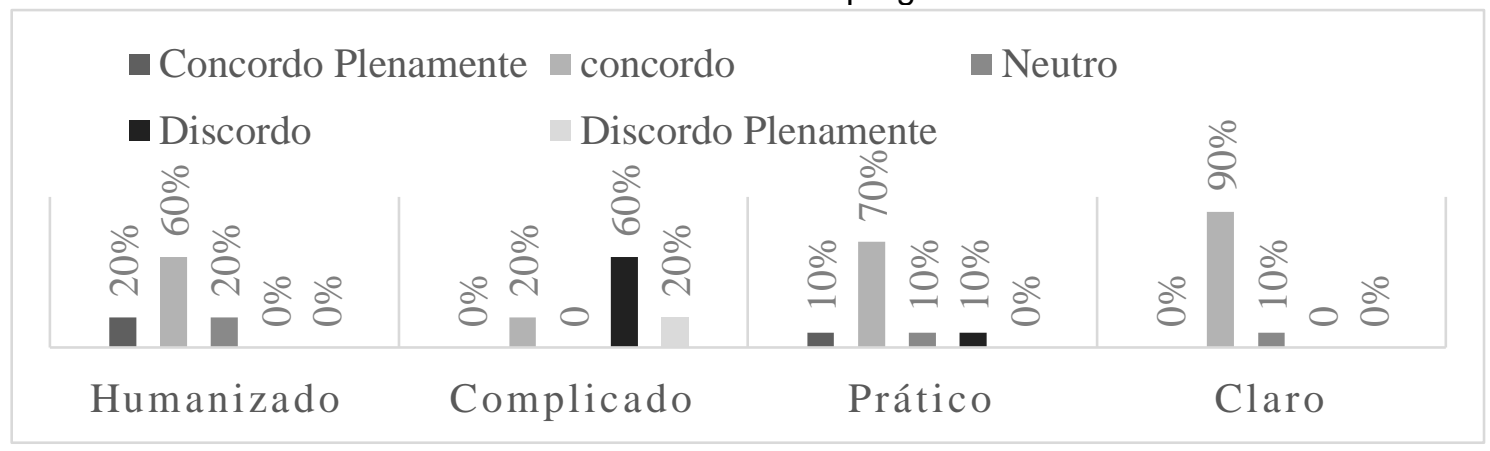

Como observado, $60 \%$ do público que vivenciou a imersão concorda que a utilização se mostra humanizada, apresentando, também pelo menos $20 \%$ de discordância (Figura 1), observando ainda que $20 \%$ concordam plenamente com a presença de característica humanísticas da experiência. Sobre complicações no uso, $60 \%$ dos envolvidos discordam que a imersão se mostra complicada em seu uso, tendo $20 \%$ de concordância.

Ainda, para entender sobre praticidade no uso e clareza da experiência, 70\% dos participantes consideram prático e $90 \%$ concordam que a experiência se dá de maneira clara. Levy (2013) destaca o virtual como uma extensão, uma potência que nos estende ao universo digital, as considerações apresentadas no (Figura 1), se mostram em consonância com as discussões do autor, uma vez que a humanização da experiência a qualifica como uma potencialidade no contato com outras realidades. 
IX Congresso Brasileiro de Informática na Educação (CBIE 2020)

Anais do XXXI Simpósio Brasileiro de Informática na Educação (SBIE 2020)

\subsection{Qualidade Hedônica}

A qualidade hedônica enfatiza o bem-estar psicológico proporcionado, aos usuários, pela experiência, nesta dimensão buscamos entender o quão confortável ou não os participantes se sentiram, assim como aspectos relacionados a originalidade, interesse e estímulo. O gráfico abaixo, relaciona de maneira a quantificar as respostas dos participantes a cada pergunta sobre as características envolvidas na dimensão hedônica (Gráfico 2).

\section{Gráfico 2- Qualidade Hedônica}

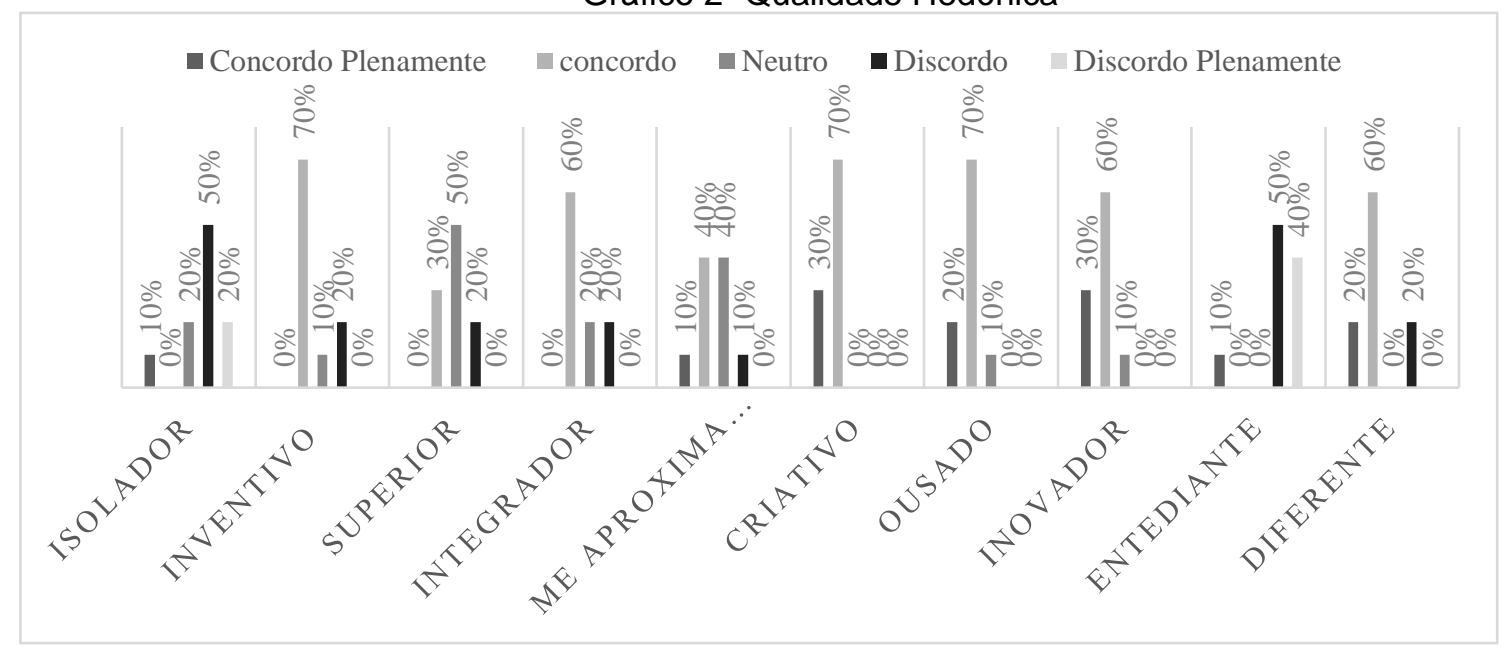

A sensação de contato proximal é um dos aspectos que se objetivou com o uso de $\mathrm{RV}$, neste contexto, pode-se destacar duas características como "isolador" em que 50\% dos participantes discordam de tal aspecto e "me aproxima das pessoas" $40 \%$ concorda com tal característica e $40 \%$ não tinham opinião formada sobre. No que diz respeito a outras características como interatividade $70 \%$ do público se mostra favorável, o que coincide com $70 \%$ de concordância sobre a criatividade presente na experiência.

Uma das preocupações envolvidas na imersão é com a atenção dos participantes, contudo ao analisarmos o caráter "entediante" do formulário, apenas $10 \%$ dos participantes definem a experiência como algo entediante. De modo geral, alguns participantes disseram se sentir realmente no ambiente proporcionado pela RV, e por ser algo novo, se tornou atraente, aspecto este que é tratado com mais ênfase na próxima sessão.

\subsection{Atratividade e aspectos gerais}

\section{Gráfico 3 - Atratividade}

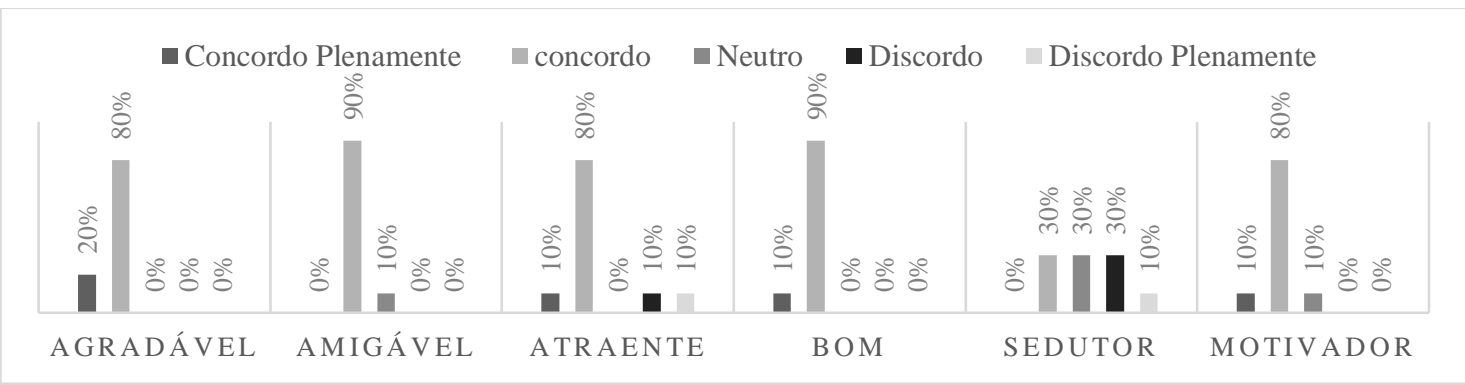


IX Congresso Brasileiro de Informática na Educação (CBIE 2020)

Anais do XXXI Simpósio Brasileiro de Informática na Educação (SBIE 2020)

Esta dimensão visa tratar do conforto e envolvimento no contato visual, das características, ergonômicas, e estéticas do objeto. De modo quantitativo, $90 \%$ dos participantes relatam a experiência com algo amigável, uma das situações que se evidenciou na preocupação sobre a aceitação da experiência foi a familiaridade com o uso dos óculos, contudo, $80 \%$ do público destaca a experiência como atraente, $80 \%$ como motivadora, além de se mostrar fortemente atraente para $80 \%$ dos envolvidos (Gráfico 3).

Visando maior aproximação com as opiniões dos participantes, sobre sua experiência de imersão, os indagamos sobre sua concepção acerca do uso da tecnologia de RV como objeto de ensino aprendizagem. As narrativas partiram dos mis diversos contextos, desde relatos sobre dificuldade até a interpretação do uso de tal tecnologia como algo inovador como podemos observar nas transcrições que se seguem:

"Acredito que seja uma maneira de inovar e aprimorar a qualidade do ensino
seja dentro das escolas ou nas universidades, pois ajuda no ensino
aprendizagem além de proporcionar novas metodologias que podem ajudar no
aperfeiçoamento do processo educacional". (Participante 2)
"É uma maneira de aprender sobre um conteúdo, interagindo de forma direta e
indireta dependendo do assunto abordado, alguns óculos de realidade
permitem interagir diretamente com o conteúdo, como o exemplo de jogos.
Permitindo assim até mesmo o aprendizado através da interação com esses
jogos de forma real/virtual". (Participante 4)

"Tem um grande potencial como ferramenta de apoio ao aprendizado" (Participante 5)

"Bom, abre os olhos das pessoas para possibilidades além do que estão comumente habituadas. " (Participante 6)

"Em primeiro Momento, é possível ter dificuldades ao se adaptar, mas tudo é uma questão de prática, levando em conta as proximidades que a experiência virtual pode te aproximar levar a ser mais perceptível as ações e as realidade fora do seu conforto." (Participante 9)

"Na minha opinião seria uma excelente ferramenta para atrair os alunos em sala de aula, tornando a aula mais divertida e interessante sem deixar é claro de repassar o conteúdo. Mas sim, uma forma didática de aprendizagem. " (Participante 10)

A leitura dos relatos reafirma aspectos relevantes sobre a Realidade Virtual. A dinamicidade, a dificuldade inicial, a possibilidade de aproximação de novas realidades dentro do contexto trabalhado, e até mesmo o potencial de ferramenta de apoio a construção da aprendizagem. As falas têm uma forte marca na discussão sobre potencial, conceito este que endossa a caracterização do virtual.

Diante disso, pode-se perceber um contexto evidentemente dialógico, onde, sob o ponto de vista freiriano a comunicação está diretamente ligada a interatividade dos sujeitos, e neste sentido interação converge entre a concepção freiriana e a emergência das novas formas de comunicação, em que na "Era dos computadores" a interatividade designa a coparticipação, comunhão humana (MALAGGI; TEIXEIRA, 2019). Esse cenário elucida a RV como além de uma ferramenta de comunicação em massa aonde a transmissão se d de maneira unidirecional.

Como percebido nos relatos dos participantes, a possibilidade de interação pertinente na RV reconfigura a tessitura da fala unidirecional para a transgressão de uma comunicação dialógica estabelecida os entre sentidos e a interação com o ambiente virtual. Ao serem indagados sobre o uso da RV para conhecer outros povos e culturas os 
IX Congresso Brasileiro de Informática na Educação (CBIE 2020)

Anais do XXXI Simpósio Brasileiro de Informática na Educação (SBIE 2020)

participantes trataram desde a sensação temporal presente, no contato com outras realidades até sensações físicas percebidas na imersão além entender como "Inovadora":

"Emocionante. Pois foi a primeira vez que tive a oportunidade de viver essa experiência. É como se estivéssemos dentro da tela virtual literalmente presenciando cada momento, cada fala, cada gesto. A medida que nós nos movimentávamos, podíamos perceber cada detalhe escondido. Simplesmente foi uma experiência inacreditável. " (Participante 2)

"É um excelente mecanismo de aproximação de realidade diferente da nossa. "(Participante 3)

“Tem se a sensação de estar ali presente, no ambiente e de estar interagindo com as ações que ocorrem durante a exibição do conteúdo. Permitindo uma experiência "em tempo real" ali naquele lugar. " (Participante 4)

"Foi incrível, e desconfortante no primeiro momento, mas é uma realidade Virtual, de suma importância que precisa de nossa atenção e que nos levou a pensar claramente por vários ângulos as realidades e os locais em que os outros estão e convivem. " (Participante 9)

"Incrível. Sinceramente foi muito bom ter vivido essa experiência. É uma forma completamente diferente de conhecer outros lugares. "(Participante 10).

\section{Considerações finais}

A Realidade Virtual, em matéria de mediação pedagógica, figura enorme potencial para auxiliar na construção do conhecimento em contextos de dificuldade no acesso a outros povos e culturas, tendo em vista a importância do contato e da observação para uma construção mais significativa do conhecimento no que diz respeito a diversidade cultural. No ambiente desta pesquisa, é possível perceber como o novo encanta e reconfigura processos de aprendizagem ao passo que convida e desafia os usuários da tecnologia.

Apesar das de alguns participantes terem se queixado de dificuldades iniciais no uso dos óculos, como posicionamento e estabilização de imagem, a proposta se mostrou produtiva. Entender a RV como estratégia de mediação pedagógica, apresenta aos estudantes e ao profissional da educação um novo olhar sobre a tecnologia, de modo que o trabalho com as tecnologias não exclui a imagem do professor, contudo possibilita aos alunos um ambiente de maior protagonismo.

Os relatos dos participantes respondem às expectativas dos pesquisadores, quando evidenciam a sensação de estar no exato lugar apresentado pela imersão, e terem conseguido assimilar as discussões com mais clareza, relatando, inclusive, terem tido possibilidade de vivenciar situações além do habitual. Frente a esta experiência é possível perceber como a ressignificação de territórios por meio da RV potencializa contato com novas culturas, sem perder a sua essência tecnológica, e entender como o virtual se apresenta como uma extensão reiterando não se opor ao real. Como proposta de continuidade desta pesquisa, objetivamos agregar conceitos de Realidade Aumentada, construindo assim um ambiente de realidade Mista.

\section{Referências}

ABARI, Omid et al. Enabling high-quality untethered virtual reality. In: 14th \{USENIX\} Symposium on Networked Systems Design and Implementation (\{NSDI\} 17). 2017. p. 531-544.

BLACK, Ethan R. Learning then and there: An exploration of virtual reality in K-12 History education. 2017. Doctoral dissertation. 
IX Congresso Brasileiro de Informática na Educação (CBIE 2020)

Anais do XXXI Simpósio Brasileiro de Informática na Educação (SBIE 2020)

BORDENAVE, Juan E. Díaz. O que é comunicação. Brasiliense, 2017.

Costa, Renata Luiza da; Souza, Maria Aparecida R. de; Júnior, Alcides Hermes Thereza. Materialismo Histórico-Dialético e pesquisas em Informática na Educação. Metodologia de Pesquisa em Informática na Educação (Série de Livros da CEIE/SBC) 2019. Disponível em: https://metodologia.ceie-br.org/\#livros. Acesso: 15 abr. 2020.

FERNANDEZ, Manuel. Augmented virtual reality: How to improve education systems. Higher Learning Research Communications, v. 7, n. 1, p. 1-15, 2017.

GIBSON, William. Neuromancer. Aleph, 2015.

HAESBAERT, R. O mito da desterritorialização: do "fim dos territórios" à multiterritorialidade. $7^{\circ}$ ed. Rio de Janeiro: Bertrand Brasil, 2004/2012.

LAVALLE, S. M. Virtual Reality/University of Illinois.[Sl:] Cambridge University Press. 418. Disponível em: http://vr. cs. uiuc. edu/vrbook. pdf, 2017.

LEANDRO, Mardem; COUTO, Daniela Paula do; LANNA, Maria dos Anjos Lara. Da realidade psíquica ao laço social: a função de mediação do conceito de fantasia. Cadernos de psicanálise (Rio de Janeiro), v. 35, n. 28, p. 27-48, 2013.

LÉVY, Pierre. Que é o Virtual?.2. ed., São Paulo: Editora 34, 2011.

MALAGGI, Vitor; TEIXEIRA, Adriano Canabarro. Comunicação, Tecnologias Interativas e educação:(re)pensar o ensinar-aprender na cultura digital.1. ed.,Curitiba: Editora Apris,2019.

MITTERMAYER, Thiago. Narrativa transmídia: uma releitura conceitual e prática. 2016. São Paulo: Editora C0D3S, 2017

ROUDINESCO, Elisabeth; PLON, Michel. Fantasia. In: Dicionário de

psicanálise. Rio de Janeiro: Jorge Zahar, 1998, p. 223-226.

SANTAELLA, L. A ecologia pluralista da comunicação: conectividade, mobilidade, ubiquidade. São Paulo: Paulus, 2010.

SANTAELLA, Lucia. O paradigma do sensível na comunicação. Revista Comunicação Midiática, v. 11, n. 1, p. 17-28, 2016.

SANTAELLA, Lucia. Comunicação ubíqua: repercussões na cultura e na educação. Pia Sociedade de São Paulo-Editora Paulus, 2013.

TONUCCI FILHO, João Bosco Moura. Espaço e território: um debate em torno de conceitos-chave para a geografia crítica. Revista Espinhaço| UFVJM, p. 41-51, 2017.

VALENTIM, Natasha M. Costa; SILVA, Williamson; CONTE, Tayana. Avaliando a Experiência do Usuário ea Usabilidade de um Aplicativo Web Móvel: Um Relato de Experiência. In: CIbSE. 2015. p. 788.

YILDIRIM, Gürkan; ELBAN, Mehmet; YILDIRIM, Serkan. Analysis of Use of Virtual Reality Technologies in History Education: A Case Study. Asian Journal of Education and Training, v. 4, n. 2, p. 62-69, 2018. 